\title{
Novel generation and transmission of 2 Gbps impulse radio ultra wideband over MMF for in-building networks application
}

\section{Citation for published version (APA):}

Abraha, S. T., Yang, H., Okonkwo, C. M., Boom, van den, H. P. A., Tangdiongga, E., \& Koonen, A. M. J. (2010). Novel generation and transmission of 2 Gbps impulse radio ultra wideband over MMF for in-building networks application. In 2010 Conference on Optical Fiber Communication, Collocated National Fiber Optic Engineers Conference, OFC/NFOEC 2010 (pp. OML4-1/3). [5465292] Institute of Electrical and Electronics Engineers.

\section{Document status and date:}

Published: 30/06/2010

\section{Document Version:}

Publisher's PDF, also known as Version of Record (includes final page, issue and volume numbers)

\section{Please check the document version of this publication:}

- A submitted manuscript is the version of the article upon submission and before peer-review. There can be important differences between the submitted version and the official published version of record. People interested in the research are advised to contact the author for the final version of the publication, or visit the $\mathrm{DOI}$ to the publisher's website.

- The final author version and the galley proof are versions of the publication after peer review.

- The final published version features the final layout of the paper including the volume, issue and page numbers.

Link to publication

\section{General rights}

Copyright and moral rights for the publications made accessible in the public portal are retained by the authors and/or other copyright owners and it is a condition of accessing publications that users recognise and abide by the legal requirements associated with these rights.

- Users may download and print one copy of any publication from the public portal for the purpose of private study or research.

- You may not further distribute the material or use it for any profit-making activity or commercial gain

- You may freely distribute the URL identifying the publication in the public portal.

If the publication is distributed under the terms of Article 25fa of the Dutch Copyright Act, indicated by the "Taverne" license above, please follow below link for the End User Agreement:

www.tue.nl/taverne

Take down policy

If you believe that this document breaches copyright please contact us at:

openaccess@tue.nl

providing details and we will investigate your claim. 


\title{
Novel Generation and Transmission of 2 Gbps Impulse Radio Ultra Wideband over MMF for In-Building Networks Application
}

\author{
S.T. Abraha, H. Yang, C.M. Okonkwo, H.P.A van den Boom, E. Tangdiongga and A.M.J. Koonen \\ COBRA Research Institute, Eindhoven University of Technology, NL-5600MB, Eindhoven, The Netherlands \\ Email:S.T.Abraha@tue.nl
}

\begin{abstract}
We propose novel generation technique of IR-UWB pulse by linearly combining two monocycles using different pulse shapes. We experimentally demonstrate DSP based BER measurement of 2 Gbps IR-UWB over multimode fiber for in-building networks application. (C)2010 Optical Society of America OCIS codes: (060.4510) Optical communications; (060.5625) Radio frequency photonics.
\end{abstract}

\section{Introduction}

Ultra-wideband has been indicated as one of the most promising techniques to be used for next generation short-range broadband wireless communications and sensor networks. The growing interest in this technique is due to its low transmission power, tolerance to multipath fading, low probability of interception, and capability of passing through walls while maintaining communication [1]. Due to the low power density $-41.3 \mathrm{dBm} / \mathrm{MHz}$ in the frequency band of 3.1-10.6 GHz regulated by the US Federal Communications Commission (FCC), the communication distances are limited, typically extending less than 10 meters. To increase the area of coverage, UWB signals should be distributed over wired lines such as coaxial cable or optical fiber. Thanks to the low loss and broad bandwidth of state-of-the-art fiber, the distribution of UWB signals over optical fiber, or UWB-over-fiber, is considered a promising solution [2].

In this paper, we experimentally demonstrate a novel and simple approach to generate fully FCC compliant 2 Gbps impulse radio ultra wideband (IR-UWB) transmission using direct modulation of an optical signal, which is adequate for $1920 \times 1080 \mathrm{i} \times 18 \mathrm{bpp} \times 60 \mathrm{~Hz}$ uncompressed video transmission [1]. Our IR-UWB pulses are generated based on the concept of linear combination of two first order derivatives of a Gaussian pulses (or monocycles) with different pulse shaping factor. The generated pulse is then transmitted over $4.4 \mathrm{~km}$ multi-mode fiber (MMF) for in-building network applications. Finally, transmission system performance evaluation based on bit error measurement (BER) is performed using digital signal processing (DSP) in a bit-for-bit comparison between the transmitted and received signals. We acknowledge the support of the EU program FP7 ICT-ALPHA project in this work.

\section{Mathematical Signal Model and Simulation Results}

We consider a weighted sum of two first-order derivatives of Gaussian pulses called monocycles using different pulse-shaping values of $\sigma_{11}$ and $\sigma_{I 2}$. The weighted sum value $y_{w s I}(t)$ is given by

$$
y_{w s 1}(t)=a_{11} x_{11}\left(t, \sigma_{11}\right)+a_{12} x_{12}\left(t, \sigma_{12}\right)
$$

where $x_{1 i}\left(t, \sigma_{I i}\right)$ is the first order derivatives of Gaussian pulses, expressed by [3]:

$$
x_{1 i}\left(t, \sigma_{1 i}\right)=\left[\frac{-2 t}{\sigma_{1 i}^{2}}\right] \exp \left(\frac{-t^{2}}{2 \sigma_{1 i}^{2}}\right)
$$

with $i=1,2$ and $\sigma_{11}=49 \mathrm{ps}, \sigma_{12}=48 \mathrm{ps}, a_{11}=0.268$ and $a_{12}=-0.5$ are the parameters used for our experiment. The Fourier transform of $y_{w s l}(t)$ is given by

$$
Y_{w s 1}(f)=a_{11} X_{11}\left(f, \sigma_{11}\right)+a_{12} X_{12}\left(f, \sigma_{12}\right),
$$

where

$$
X_{1 i}\left(f, \sigma_{1 i}\right)=(j 2 \pi f) \exp \left(-\frac{\left(2 \pi f \sigma_{1 i}\right)^{2}}{2}\right)
$$


The simulation result of each monocycle pulse is shown in the Fig.1a. The resulted pulse after linear combinations of the pulses with their appropriate weighting coefficient is depicted in Fig. $1 \mathrm{~b}$ and its corresponding spectral density compared with FCC mask is shown in Fig. 1c. According to our simulation result shown in Fig. 1c, we observe that the newly designed IR-UWB pulse can fit the FCC-mask better than the conventional monocycle and doublet pulses even in the most severely power-restricted band from $0.96 \mathrm{GHz}$ to $1.61 \mathrm{GHz}$. Furthermore, the approach avoids the requirement of higher order derivative of Gaussian pulses such as the fifth-order derivative recommended by [3]. Hence, the novelty of our approach lies in using low-order derivative of Gaussian pulses, which can reduce the complexity and cost of the system and also efficiently fits the FCC mask requirements. Due to the sidelobes created in the basic shape of the monocycle, our pulse has more zero crossing compared to the conventional monocycle and doublet pulse, which moves the energy of the pulse to higher frequency ranges with similar effect as higher derivatives of Gaussian pulse. Furthermore, our IR-UWB is efficient for transmission using antenna systems because most of the energy lies in higher frequency band.

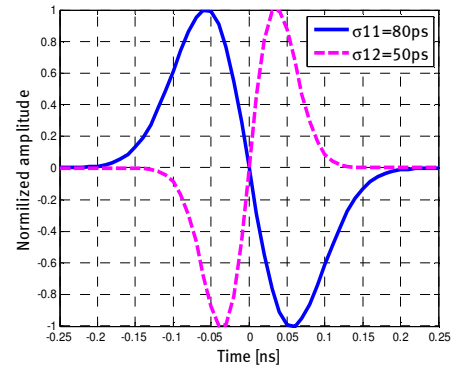

Fig. 1a: Monocycle pulses

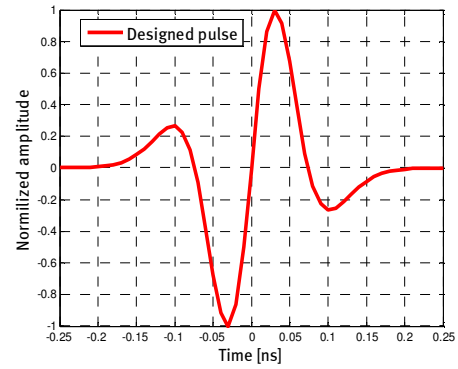

Fig. 1b: Designed IR-UWB pulse

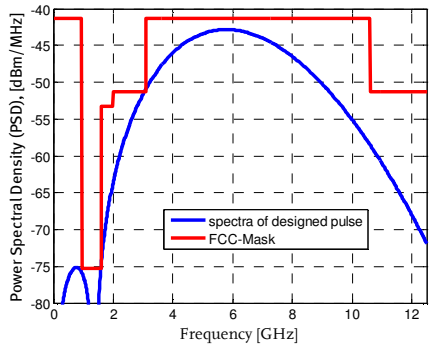

Fig. 1c: Spectrum of designed IR-UWB and FCC mask

\section{Experimental Setup}

Based on the above principle, an experiment setup is shown in Fig.2. The PRBS of $2^{13}-1$ data from PRBS generator block, IR-UWB pulse from pulse shaper block and on-off modulation process have been constructed off-line and then the modulated pulse is sent to the arbitrary waveform generator (AWG) running at $24 \mathrm{GSamples} / \mathrm{s}$. The generated electrical IR-UWB signal output from AWG modulates a DFB laser at $1302.56 \mathrm{~nm}$ wavelength, which is the zero dispersion region of the fiber. We choose direct modulation in order to be cost effective for in-building network application. Then the modulated optical signal was transmitted over 4.4-km MMF and detected by a $25 \mathrm{GHz}$ photo-detector (PD). A lower bandwidth photo-detector $(\sim 10 \mathrm{GHz})$ can be used here without significant signal degradation. A real-time Digital Phosphor Oscilloscope (DPO) running at a sampling rate of $25 \mathrm{GSamples} / \mathrm{s}$ is used to measure the time-domain waveform and collect data for offline processing for demodulation and BER measurements. Finally, an RF spectrum analyzer to present the electrical spectrum of our pulse and compare it to the FCC mask requirement.

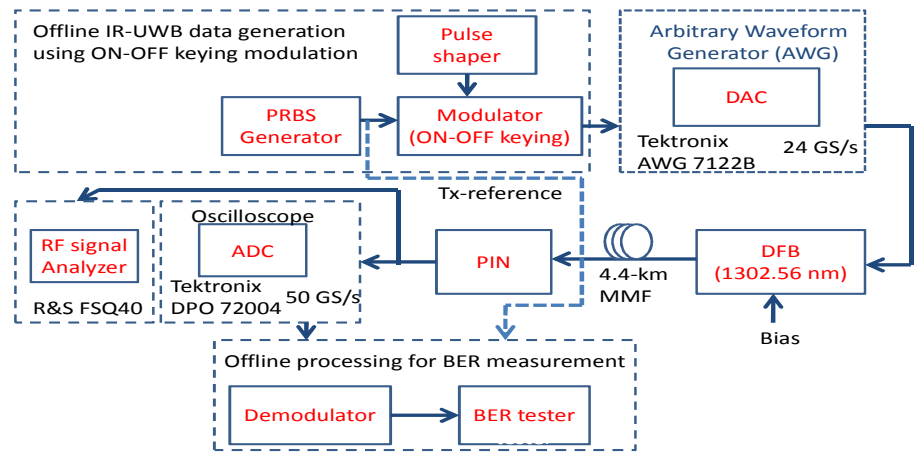

Fig. 2: Experimental setup

\section{Experimental Results and Discussions}

Several modulation formats can be used for IR-UWB [4], however for simplicity and low-cost reason we use on-off keying (OOK) of PRBS $2^{13}-1$ pattern length. Fig. 3a shows part of the transmitted data taken during the optical back to back measurement and clearly shows the on-off keying modulation of a binary sequence of 8 bits " 01110 10 0". The spectrum of our generated IR-UWB is fully compatible with FCC mask, which has a central frequency 


\section{OML4.pdf}

of $5.63 \mathrm{GHz}$ and a 10-dB bandwidth of $6.36 \mathrm{GHz}$ is shown in Fig.3b. Due to the on-off keying modulation scheme, the spectrum shows discrete spectral line called comb lines where the spacing between each comb lines is $2 \mathrm{GHz}$ which exactly equal to the bit-rate of the transmission system. The envelope of the spectral lines corresponds to spectrum of our IR-UWB pulse and their peak power spectral density (PSD) must reamin below the FCC mask in order to avoid interfernce to other operating wireless systems, which finally can limit the total transmitted power. After 4.4-km MMF transmission, the time-domain waveform is shown in Fig. 3c. The result clearly shows no significant distortion of the pulse other than reduction in amplitude, which leads to low signal-to-noise ratio (SNR) at the receiver side. Fig. 3d finally shows the spectrum of the received IR-UWB signal after 4.4-km MMF transmission. The signal spectrum is still very nicely fitting into FCC mask without distortion.

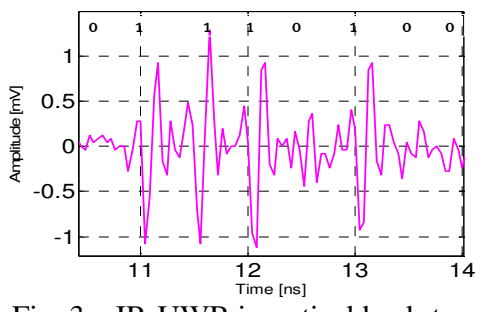

Fig. 3a: IR-UWB in optical back-toback case

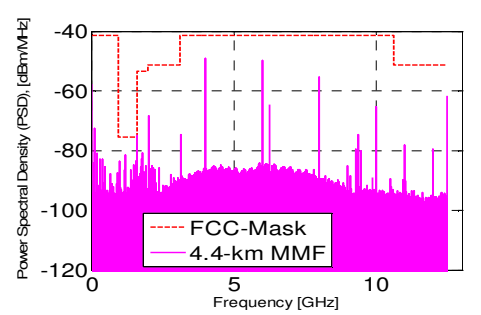

Fig. 3d: Spectrum of IR-UWB after $4.4 \mathrm{~km}$ MMF and FCC mask

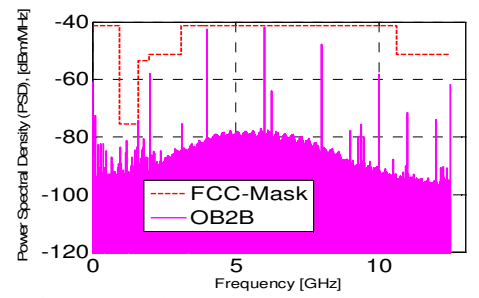

Fig. 3b: Optical back-to-back spectrum of IR-UWB and FCC mask

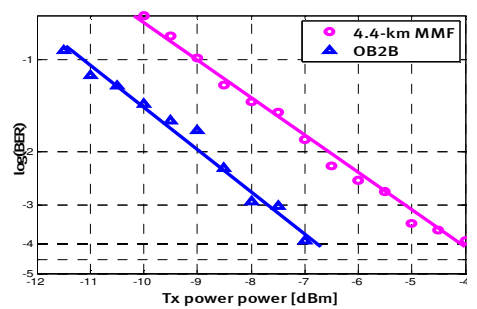

Fig.3e: BER measurement of optical backto-back and 4.4km MMF fiber transmission

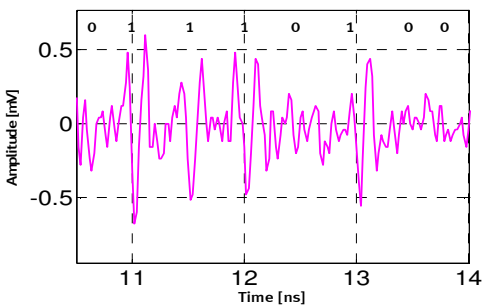

Fig. 3c: IR-UWB after 4.4-km MMF

Figure 3e, shows the BER results of 2 Gbps IR-UWB signal transmissions. For each BER measurement points 8190 bits following a $2^{13}-1$ PRBS pattern are transmitted and recorded using a 25 GSamples/s digital oscilloscope. The BER is subsequently computed using a DSP algorithm in a bit-for-bit comparison between the transmitted and received data. The DSP algorithm distinguished between binary " 1 " and " 0 " by comparing the average power within the central window of each bit slot to an adaptive decision threshold. This approach is expected to provide more accurate results than BER estimates from the eye diagram Q-factor as in [1]. According to the result of the BER measurement, the 4.4-km MMF transmission shows a penalty of almost $3 \mathrm{~dB}$, this is largely caused by modal noise at the receiver side due to the mismatch of $25-\mu \mathrm{m}$ photodetector and 50- $\mu \mathrm{m}$ core MMF. In general, the experimental result shows a successful transmission of forward error free (FEC) limit of IR-UWB over multimode fiber for inbuilding application.

\section{Conclusions}

We propose novel generation technique of IR-UWB pulse by linearly combining two monocycles using different pulse-shaping factors. We experimentally demonstrate for the first time an FEC-limit DSP based BER measurement of 2 Gbps IR-UWB over $4.4 \mathrm{~km}$ multimode fiber with fractional bandwidth of about $113 \%$. The generated pulse fully complies with the FCC-indoor spectrum mask even in the most severely power-restricted band from $0.96 \mathrm{GHz}$ to $1.61 \mathrm{GHz}$. We believe that our newly proposed IR-UWB over MMF has a potential application in high speed short-range communications networks such as in-building networks.

\section{References}

[1] R. Llorente, T.Alves, M.Morant, M.Beltran, J.Perez, A. Cartaxo and J. Marti, "Ultra-wideband radio signals distibution in FTTH Networks," IEEE Photon. Technol. Lett., vol. 20, no. 11, pp. 945-947, Jun. 2008

[2] J. Yao, "Photonics for Ultra Wideband communications," IEEE Microw. Mag., vol. 4, no. 2, pp. 82-495, Jun. 2009

[3] H. Sheng, P. Orlik, A.M. Haimovich, L.J. Cimini and J. Zhang, "On the Spectral and Power Requirements for ultra Wideband Transmisssion," IEEE Int. Conf. on Commn.., vol. 1, pp. 738-742, May 2003

[4] M. Ghavami, L. B. Michael, and R.Kohon, Ultra Wide-Band Signals and Systems in Communication Engineering. West Sussex, England: Wiley, 2007 